
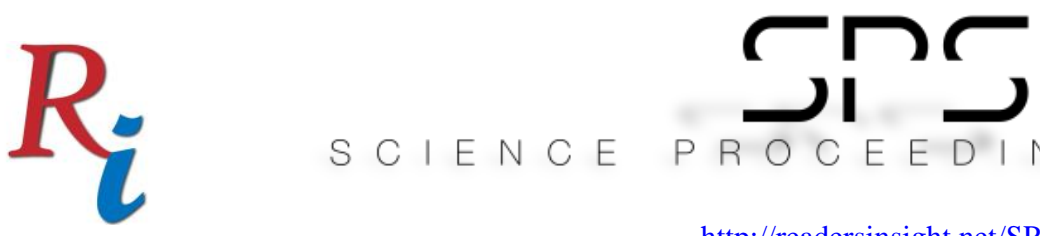

SCIENCE PROCEEDINGS SERIES

http://readersinsight.net/SPS

\title{
POTENTIAL OF GRANITE DUST TO IMPROVE THE ENGINEERING PROPERTIES OF SOFT SOILS FOR ROAD CONSTRUCTION
}

\author{
Ahmed Salama Eltwati* \\ Department of Road and Airport Engineering \\ Bright Star University \\ Libya \\ Ahmed.Eltwati@bsu.edu.ly \\ Alaa A. A. Elkaseh \\ School of Civil Eng., Faculty of Engineering \\ Universiti Teknologi Malaysia \\ Malaysia \\ alaaelkaseh@gmail.com \\ Fares Tarhuni \\ High Institute for Engineering Profession \\ Libya \\ Fst257@gmail.com \\ Saleh Ahmeed Buagela \\ Department of Engineering Science \\ Bright Star University \\ Libya \\ Saleh.ahmeed87@gmail.com
}

*Corrosponding author's Email: Ahmed.Eltwati@bsu.edu.ly

Peer-review under responsibility of 4th Asia International Multidisciplinary Conference 2020 Scientific Committee http://connectingasia.org/scientific-committee/

(C) 2020 Published by Readers Insight Publisher, lat 306 Savoy Residencia, Block 3 F11/1,44000 Islamabad. Pakistan,

editor@readersinsight.net

This is an open access article under the CC BY-NC-ND license (http://creativecommons.org/licenses/by-nc-nd/4.0/). 

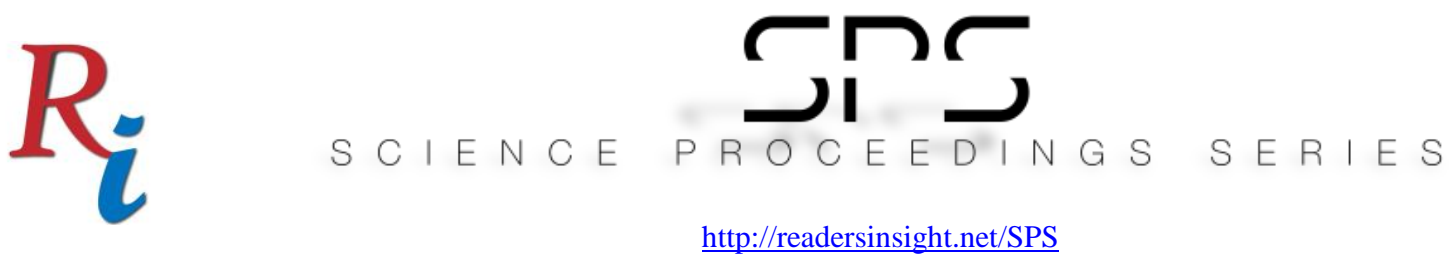

\section{A b s t r a c t}

Soft soils such as clayey soils, mostly if the soils comprise swelling elements may produce great loss to highway pavement, particularly if the soils are exposed to water. The chemical additives may improve the engineering properties of soil. In this paper, granite waste dust was utilized to evaluate the possibility to develop the strength of clayey soils. This research investigates the effect of deposited granite dust on the properties of soft soils. The Atterberg limits, particle size distributions, dry density, bearing capacity and shear strength of the soil were evaluated. The natural soil was treated with different percentages of granite dust $(0 \%$, $4 \%, 8 \%, 12 \%, 16 \%$, and $20 \%$ by total weight of soil). The findings display a great improvement in the maximum dry density (MDD), optimum water content, direct shear strength and CBR with intensifying the amount of granite dust. The MDD and CBR were improved from $1.59 \mathrm{~kg} / \mathrm{cm}^{3}$ and $3.6 \%$ to $1.88 \mathrm{~kg} / \mathrm{cm}^{3}$ and $17 \%$ respectively. The best results obtained for CBR values were when the soils mixed with $9 \%$ granite dust. Although these findings indicate a great enhancement in the characteristics of clayey soils, the superior performance established is not sufficient if the soils utilized in the base course for roads with high traffic volume. However, this modified material can be suitable for the subbase course and subgrade.

Keywords: Clayey Soil; Geotechnical Properties, Stabilization; CBR; Strenght

\section{Rese a r ch H igh I ight s}

- The findings revealed that the geotechnical properties of clayey soils are enhanced considerably by the adding of deposited granite dust.

- The results have shown that mixing the clayey soil with the granite dust $\mathrm{m}$ improved the maximum dry density. Adding content of $8 \%$ of the granite powder to the untreated soil attains the best results.

- There is a great development in the strength of modified soil made with granite dust. The result showed that the values of CBR of treated soil increased as the percentage of the granite powder in the sample increased. The optimum granite dust content was $8 \%$.

- The direct shear test showed that there was a noticeable indication of shear stress enhance as shear strain. Also, the study found that normal stress gets higher as the shear stress elevates. The shear strength of modified soils with granite dust is 3 times better than untreated soils 

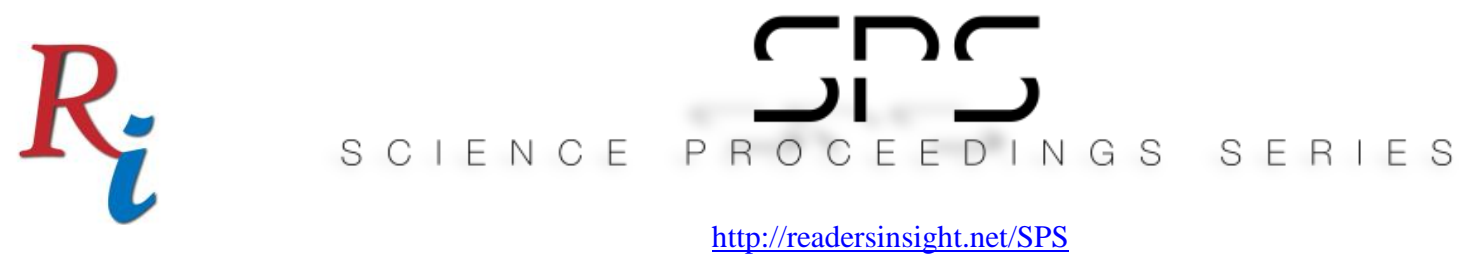

\section{Graphical A bstract}

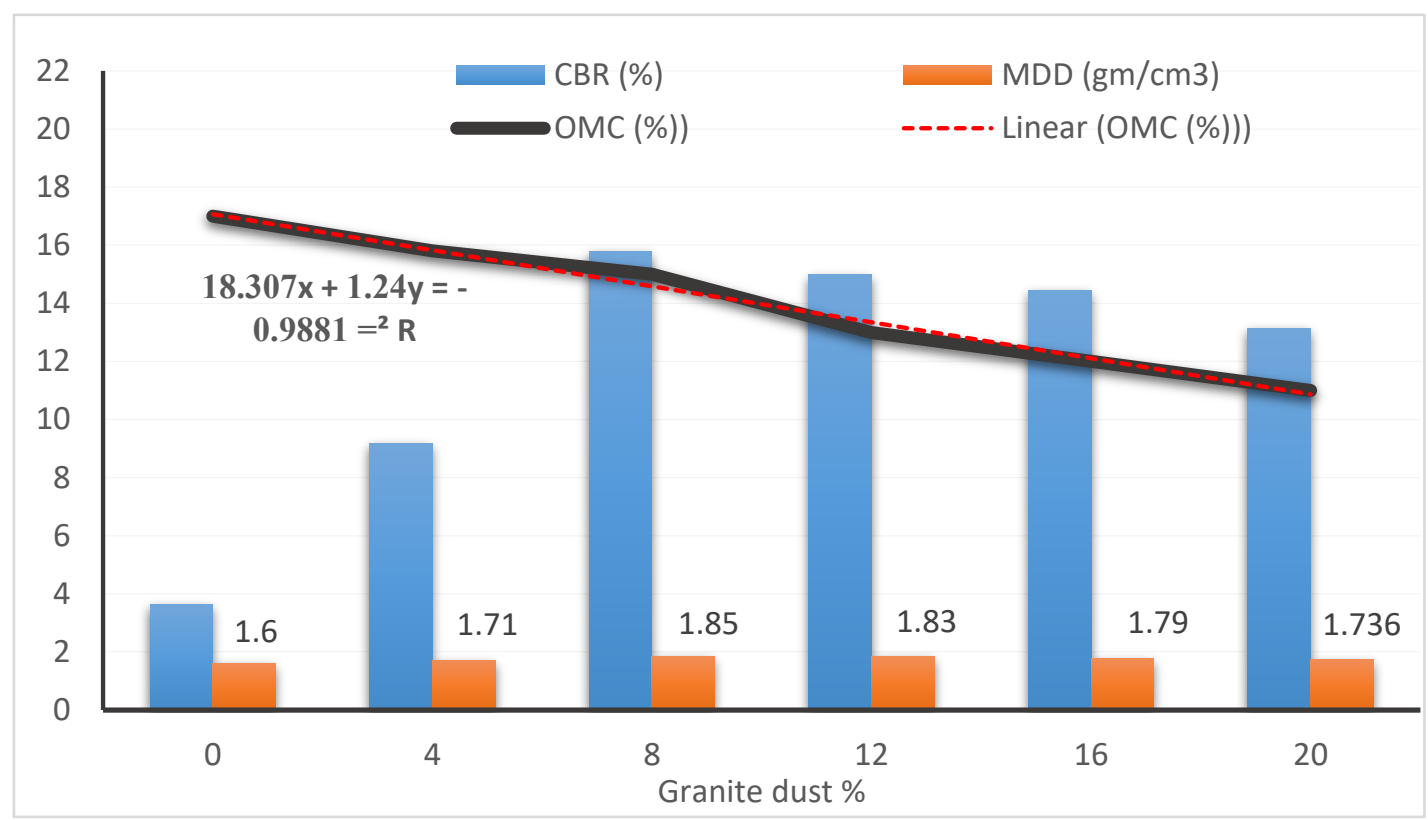

Fig. 1: The effect of granite dust on CBR, MDD, and OMC

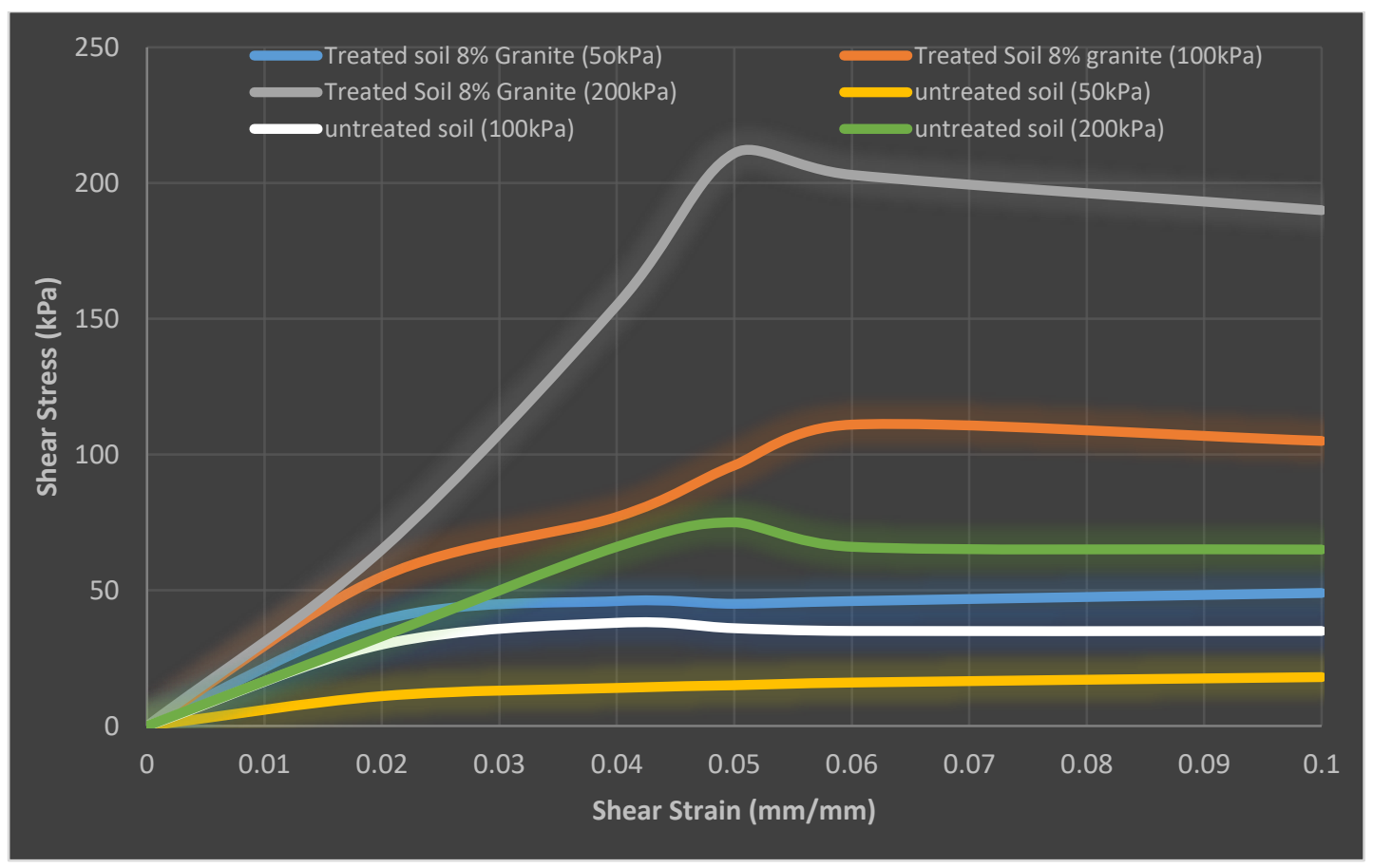

Fig. 2: The relationship between shear stress vs. shear strain on treated soil and natural soil 

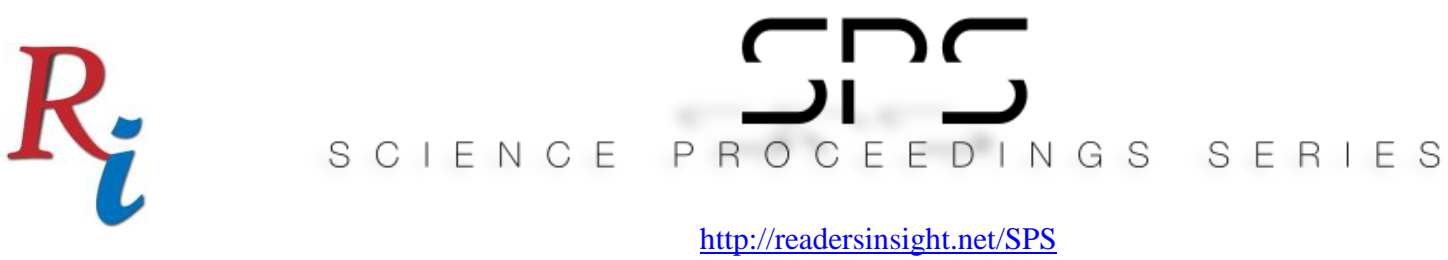

\section{Research Objectives}

The flexible pavement is highly dependent on the performance of underlying layers, particularly the subgrade (1-3). Several studies have recently been done to enhance the engineering properties of clayey soils. Therefore, this research aimed to improve the properties of subgrade. This experiment investigates the effect of granite dust on high-plasticity clay soil. The parameters examined were bearing capacity, MDD, OMC, particle size distribution, and shear strength. The performance of these parameters with a changing amount of the granite powder was utilized to evaluate the efficiency or otherwise of granite powder in enhancing the engineering properties of soft soils.

Several CBR tests, standard proctor tests, and direct shear tests were done on several soil samples mixed with different contents of granite dust $(0 \%, 4 \%, 8 \%, 12 \%, 16 \%$, and $20 \%$ by total weight of soil). This research aims to obtain the optimum content of granite dust that produces the best values of CBR, MDD and shear strength

\section{Methodology}

The materials used in this project were deposited granite powder and clayey soil. The granite dirt was obtained from a local factory. The natural soil utilized in this experiment was obtained from near the military airport of Elmarj. In preparing the soil for the tests, several preliminary tests were done. The preliminary tests were sieve analysis, Atterberg limits, and chemical analysis of soil. From the AASHTO Classification System, the natural soil is classed as A-6 (very plastic clayey soils). The liquid limit, plastic limit, and plasticity index of soil were $39.3 \%, 22.4 \%$, and $16.9 \%$ respectively. According to the chemical analysis, the main constituents of granite dust are $\mathrm{SiO}_{2}$ (silica) (72.9\%), $\mathrm{AlsO}_{3}$ (alumina) (15.3\%), and $\mathrm{K}_{2} \mathrm{O}$ $(4.53 \%)$.

To prepare the samples for testing, various amounts of granite powder $(4 \%, 8 \%, 12 \%, 16 \%$ and $20 \%$ by the weight of soil) were blended to the soils. The direct shear experiment was conducted on several samples with changing the amount of granite dust. The degree of loading was kept at $0.5 \mathrm{~mm} / \mathrm{min}$. The specimens were subjected to various rates of standard stresses. The CBR test was executed to determine the bearing capacity of the natural and modified soils. The Proctor compaction experiment was performed to ascertain the dry density of soils and OMC. Figure 1 exhibits the results of MDD, OMC, and CBR for all samples. While Figure 2 manifests the result of direct shear strength. 


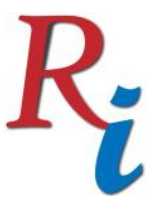

$S C \mid E N C E$

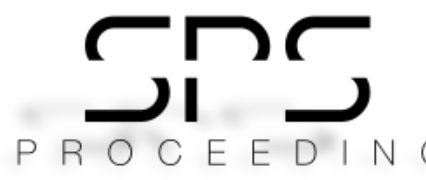

http://readersinsight.net/SPS

\section{Results}

The MDD of the soft soil improved with the heightening of the content of granite powder in soil. It is revealed in Figure. 1 that the highest value of MDD is $1.88 \mathrm{gm} / \mathrm{cm} 3$, which characterizing the treated soil with $9 \%$ granite powder. On the other hand, the MDD of the natural soil $1.599 \mathrm{gm} / \mathrm{cm}^{3}$. Therefore, it can be concluded that the MDD of soil was increased by about $16 \%$.

Figure1 shows that as the percentages of granite dust in the soil elevate, the ratios of CBR increase. The highest ratio of CBR reached was $15.8 \%$, that is corresponding to the treated soil with $8.00 \%$ granite powder. The lowest value recorded was when the soil is untreated with granite dust (CBR was 3.65\%).

From Figure 2, the shear stress rises as shear strain escalates. the rise of the shear stress was extremely reliant on the rise of its normal stress. From Figure2, the untreated soil achieved its greatest shear strength with $18.33,39.23$, and $75.36 \mathrm{kPa}$ subjected to stresses of 50,100, and $200 \mathrm{kPa}$, respectively. On the other side, the soil mixed with $8 \%$ of granite dust powder attained its highest shear strength with $50.2,118.72$, and $221.76 \mathrm{kPa}$ for stresses of 50,100 , and $200 \mathrm{kPa}$, correspondingly

\section{Findings}

The improvement in MDD and CBR indicates that waste powder operates as a greasy film on the exterior side of soil grains, reducing the absorption of water, and this eases the compaction, thus improving the connecting of soil grains along with MDD and CBR. Also, it can be concluded that mixing soil with $9 \%$ of granite dust powder improved the shear strength nearly 3 times higher than untreated soil. This result is consistent with previous researches (4-12) done on soils mixed with igneous rock i.e. marble dust. However, the previous studies have not investigated using other types of igneous rock such as granite

\section{REFERENCES}

[1] Minhans A, editor Influence of Composite Traffic Control Mechanisms on Four-Arm Highway Intersection. CSCE General Conference; 2011.

[2] Abdelgalil A, Nor H. The Effect of Joint Width on Structural Performance of Asphalt Block Pavements. Research Journal of Applied Sciences, Engineering and Technology. 2014;7(8):1612-7.

[3] Ben-Edigbe J, Abdelgalil A, Abbaszadehfallah I. Extent of Delay and Level of Service at Signalised Roundabout. International Journal of Engineering and Technology. 2012;2(3):419-24.

Copyright $($ ) 2020 Authors. This is an open access article distributed under the Creative Commons Attribution License, which permits unrestricted use, distribution, and reproduction in any medium, provided the original work is properly cited. 

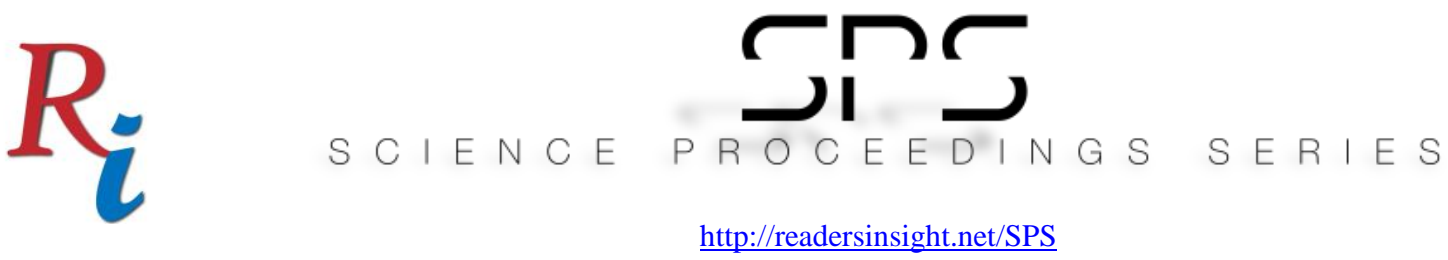

[4] Abdelgalil A, Nor H. The Influence of Block Thickness on the Performance of Asphalt Paving Blocks. Research Journal of Applied Sciences, Engineering and Technology. 2014;7(10):2129-34.

[5] Eltwati AS, Hossein A, Nasr D. Effect of Crumb Rubber Particles on the Properties of Asphalt. ICACE 2019: Springer; 2020. p. 43-52.

[6] Eltwati AS, Saleh F. Improvement of Subgrade Soils by Using Marble Dust-(Libya, Case Study). The International Journal of Engineering and Information Technology (IJEIT). 2020;6(2):40-4.

[7] Phanikumar B, m JR, e RR. Silica fume stabilization of an expansive clay subgrade and the effect of silica fume-stabilised soil cushion on its CBR. Geomechanics and Geoengineering. 2020;15(1):64-77.

[8] Jain AK, Jha AK. Improvement in Subgrade Soils with Marble Dust for Highway Construction: A Comparative Study. Indian Geotechnical Journal. 2020:1-11.

[9] Deboucha S, Sail Y, Ziani H. Effects of Ceramic Waste, Marble Dust, and Cement in Pavement Sub-base Layer. Geotechnical and Geological Engineering. 2020:1-10.

[10] Das C, Ghosh A. Study on River Bed Material and Numerical Analysis of Stabilized Road Embankment on Soft Soil. Advances in Computer Methods and Geomechanics: Springer; 2020. p. 475-88.

[11] Alnuaim A, Dafalla M, Al-Mahbashi A. Enhancement of Clay-Sand Liners Using Crushed Limestone Powder for Better Fluid Control. Arabian Journal for Science and Engineering. 2020;45(1):367-80.

[12] Mina E, Kusuma R, Ulfah N, editors. Utilization of steel slag and fly ash in soil stabilization and their effect to california bearing ratio (CBR) value.(Case study: Kp. Kadusentar road Medong village Mekarjaya Subdistrict Pandeglang District). IOP Conference Series: Materials Science and Engineering; 2019: IOP Publishing.

Author's Biography

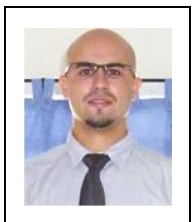

Ahmed Salama Eltwati received his master's degree in Highway \& Transportation Eng. from Universiti Teknologi Malaysia in 2010. Then, he pursued his Ph.D. study in Highway Engineering at Universiti Teknologi Malaysia and got his Ph.D. in 2015. He has 3 years of site experience in infrastructure and building work from 2006 to 2009. He has published several Scopus/ISI indexed journals. Currently, he is the dean of the faculty of aeronautics in the Bright 

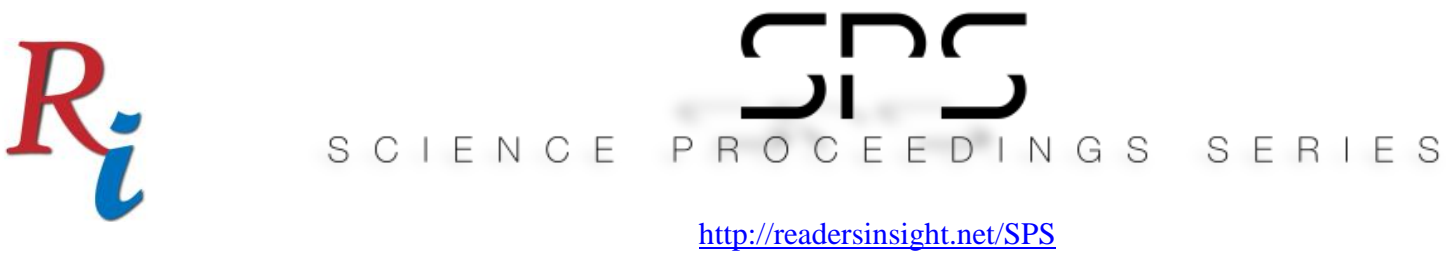

Star University of Libya. His research interest focuses on the development of rut and fatigue prediction models for flexible pavement and study of recyclable materials in asphalt concrete and soil.

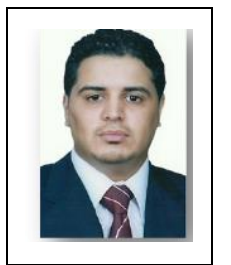

Alaa A. A. Elkaseh is a Ph.D. candidate in the School of Civil Engineering University Teknologi Malaysia. He received his bachelor's degree in civil engineering from the University of Omer ALmukhtar in 2001and his master's degree in Civil Engineering in 2009 from Universiti Teknologi Malaysia. His research interest is in the field of management engineering He is an academic staff at the High Institute for Engineering Profession in Benghazi, Libya.

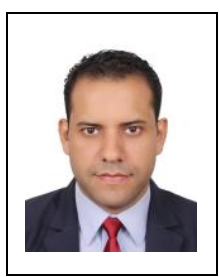

Fares Tarhuni, Lecturer at the High Institute for Engineering Professions, Libya. Born in Benghazi, July 25, 1984. Master's degree in Transportation \& Highway Engineering (UTM) and a second Master's degree in Construction Management (UTM). Research interest in the field of Highway material and material management

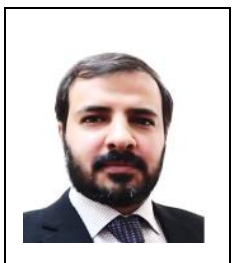

Saleh Ahmeed Buagela, a senior lecture at Bright star university Elbrega.I enrolled in civil engineering at the University of Benghazi and graduated in 2012, then I got a master's degree from UTHM University in Malaysia in 2015 and civil engineering enabled me to study design concepts and analyze various civil installations, such as buildings Residential, service, roads, bridges, and practical tunnels 